\title{
Research into vertical axial elements in seasonally frozen grounds
}

\author{
Sergey Kudriavtcev ${ }^{1 *}$, Alexey Kazharsky ${ }^{1}$, Dmitry Maleev ${ }^{1}$, Dmitry Tsvigunov ${ }^{1}$, and Vlad \\ Trapeznikov ${ }^{1}$. \\ ${ }^{1}$ Far Eastern State Transport University, Serysheva, 47, Khabarovsk, 680021, Russia
}

\begin{abstract}
The paper considers the research into the work of vertical axial elements in seasonally frozen grounds under dymanic strain within the frameworks of annual cycle. The authors provide the results of laboratory research into the specific adhesion and dynamic strain impact. They also have developed a structure capable of reducing the impact from frost heaving anf dynamic impact forces during thaw period.
\end{abstract}

\section{Introduction}

Reconstruction of power supply and transport structures in the territory of the Far Eastern Federal District (FEFD) is seriously complicated by severe natural and climatic conditions and rough geological and engineering conditions in view of long winter period and depth of frost exceeding 3 meters. New prospects for the development of Russian economy depend upon the increase in the rate of exploration of the northern and arctic regions of FEFD. This requires well-developed infrastructure - railways and highways, power lines, etc. Therefore, stability, reliability and durability of vertical axial elements (VAE) of structures become an issue of an urgent practical importance as the foundations of these structures being located in seasonally frozen grounds are exposed to freezing, frost heaving and thawing which when accompanied by vibration dynamical strain constitutes especially harsh operation conditions especially during the periods of seasonal freeze-and-thaw. Ptotection measures against these processes considerably increase expenses on the reconstruction and maintenance of vertical axial elements which makes expedient search for constructional resolutions aimed at the decrease in these expenditures [1-7].

\section{Stabilomater research into the the impact from water content on the strength properties of the soils}

Displacements of VAE are the major cause of inadmissible deformations of the foundations of structures in the regions with seasonally frozen grounds if those foundations were constructed without taking measures to exclude or reduce the deformation of foundations during springautumn periods. In this connection, we have conducted a research into the changes of stregnth and deformation properties of grounds in relation to the water content as these are the major parameters of sagging of the foundations of structures [8-13]. The research was aimed at the establishment of correlation dependency of the shear stregnthon the water content. This

\footnotetext{
${ }^{*}$ Corresponding author: prn@festu.khv.ru
} 
parameter is taken into consideration as a constituent of the simulation model for melting ground of foundations.

Pulverescent loam soils were investigated by triaxial test in accordance with State Standard GOST 12248-96 [3.3]. The triaxial test conducted determined the angle of internal friction $\varphi$, the specific cohesion $c$, the undrained shear stregnth $C_{u}$, the total strain module $E_{o}$ and the lateral strain ratio $v$ for pulverescent loamy soils in the southern regions of the Russian Far East.

Stregnth and deformation properties of the grounds under study were determined by the results of stabilometric testing of cylindrical test pieces of soils in the triaxial compression chamber of the measuring and computing system ASIS, developed by OOO « R\&D Enterprise « Geotech » [3.4].

ASIS measuring and computing systems are complexes of mechanical units (devices) integrated by functional principle, measuring system and soft ware of the « ASIS » measuring and computing system. The major functional specific features of the ASIS measuring and computing system is as follows :

- the testing process in the devices of the complex (application of load and load relief on the soil samples) are performed automatically;

- vertical and horizontal loads are applied to the samples under study;

- the system measures vertical and horizontal loads affecting the samples under study as well as the vertical, horizontal and radial deformations in the samples;

- measurement results are processed to further perform csalculations and determine stregnth and deformation properties of the soil samples under the study;

- measurement and calculation results are archived and visualized.

According to GOST 5180-84 [3.3] the samples under study had the following dimensions : $76 \mathrm{~mm}$ high and $38 \mathrm{~mm}$ in diameter. In order to determine the undrained shear stregnth of water saturated grounds, we adopted the scheme of unconsolidated-undrained triaxial compression test. Water content in the sample, as a critically important parameter of the ground condition, was measured before and after testing.

We conducted testing in rows, 3 tests for each value of the water content in soil. Fig. 1 presents the result of testing very soft loam at the water content $\mathrm{w}=31 \%$.

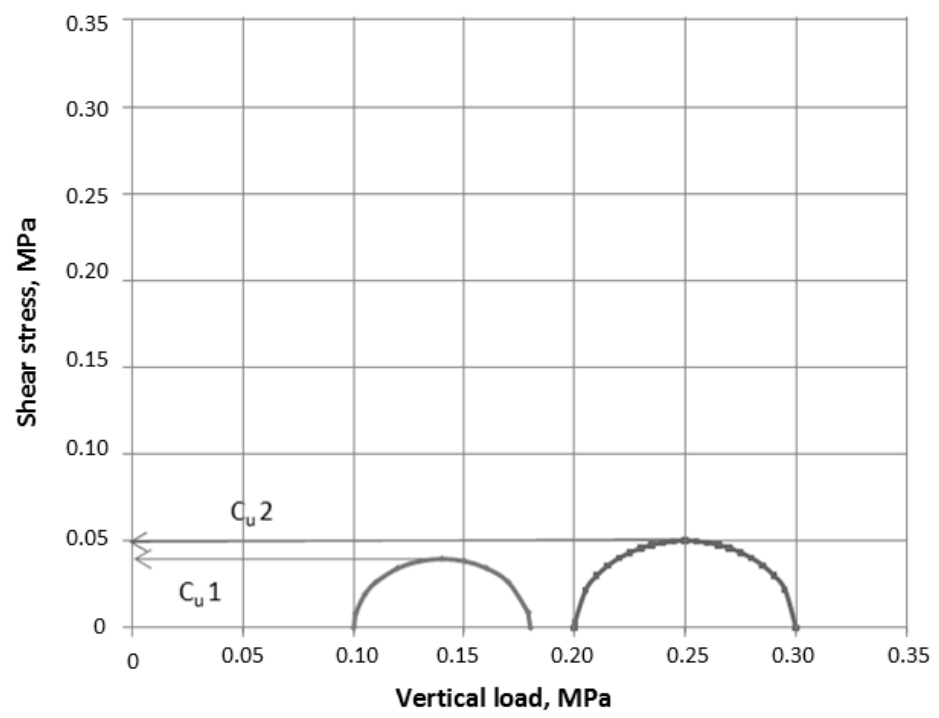

Fig. 1. Determining shear resistance $c_{u}$ of very soft loam at the water content $w=31 \%$ 
According to the results obtained, adhesion factor is $0.045 \mathrm{MPa}$, and shear resistance $\mathrm{Cu}=$ $0.045 \mathrm{MPa}$

We have conducted more than 30 testings of pulverecent loams from the southern territories of the Far East. Proceeding from earlier research into the shear resistence of clay soils depending on the water content within the wide range of its changing we made a general scatter graph (Fig. 2 ), which considerably influences the configuration of the stress and strain behavior.

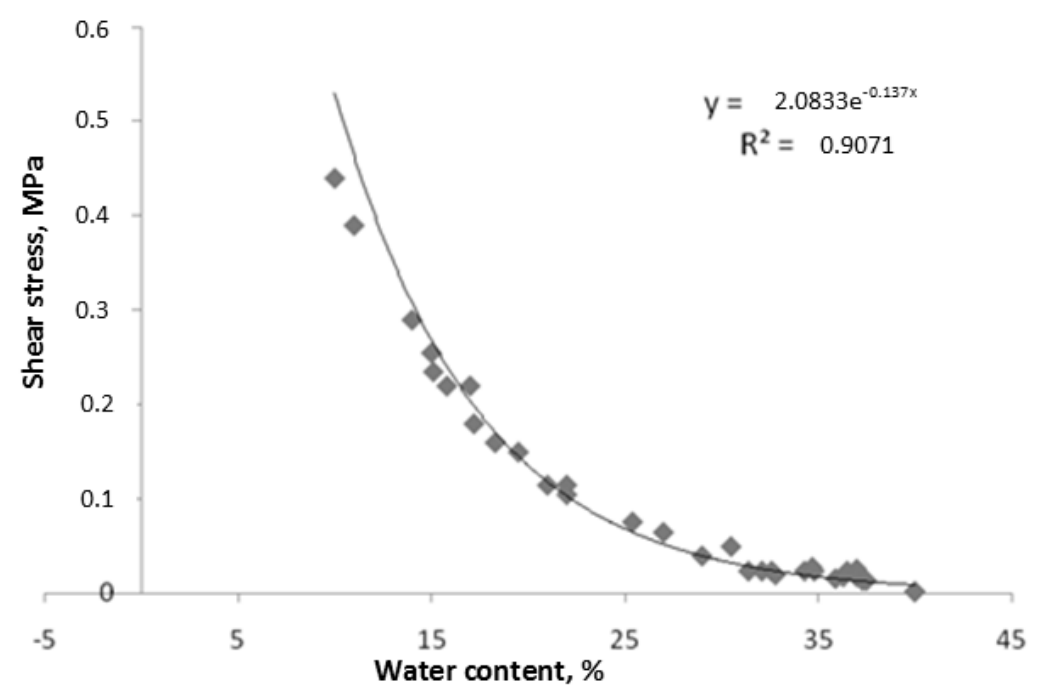

Fig. 2. Scatter diagram for undrained shear stregnth depending on the water content

As is seen from Fig. 1 the values of undrained shear stregnth vary with a wide range. Thus, procedding from the study conducted, we derived a parabolic equation of water content dependency for undrained shear stregnth. This equation allows us to restrict the scope of future research aimed at the development of simulation model of grounds behavior during the thawing period.

$$
C_{u}=2,0833 \cdot e^{-0.137 \cdot w}
$$

Results of research into the correlation dependency of the shear stregnth on the water content allowed us to develop a simulation model for foundation grounds during the thawing period. This simulation model is applied to the foundation grounds of transport structures for computer modelling of the work of rodust structures by the finite elements method.

\section{Research into vibration-dynamical impact on the foundation soils of vertical axial elements}

We used vertical geophones GX-20DX SUPER (with the bandwidth upperlimit of 2000Hz) and seismograph «Seismolog» 20/24 to record ground movements (Fig. 3). Record length in the reports was 1024 and the sampling period was 0.125 millisecond. Magnitude ratio of the inpur circuite equaled 50 and no instrument filtering operations were applied. 


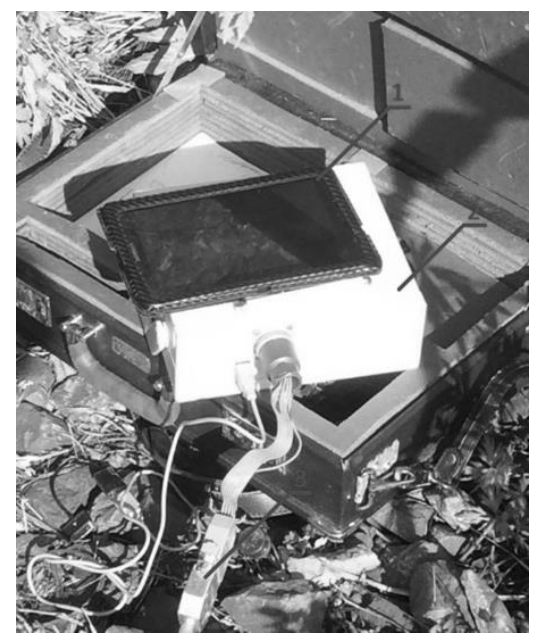

Fig. 3. Hardware-soft ware complex employed in the research: 1 - tablet computer; 2 - seismograph «Seismolog» 20/24 equipped with a built-in rechargeable battery; 3 - mount connector for seismometer cable with a set of gages «Geophone» GX-20DX-super;

After decoding and processing of the recorded data of the ground motion process we obtained the following result: vertical axial elements experience maximum vibration-dynamical train in spring during the period of thawing out of the foundation grounds (Figure 4).

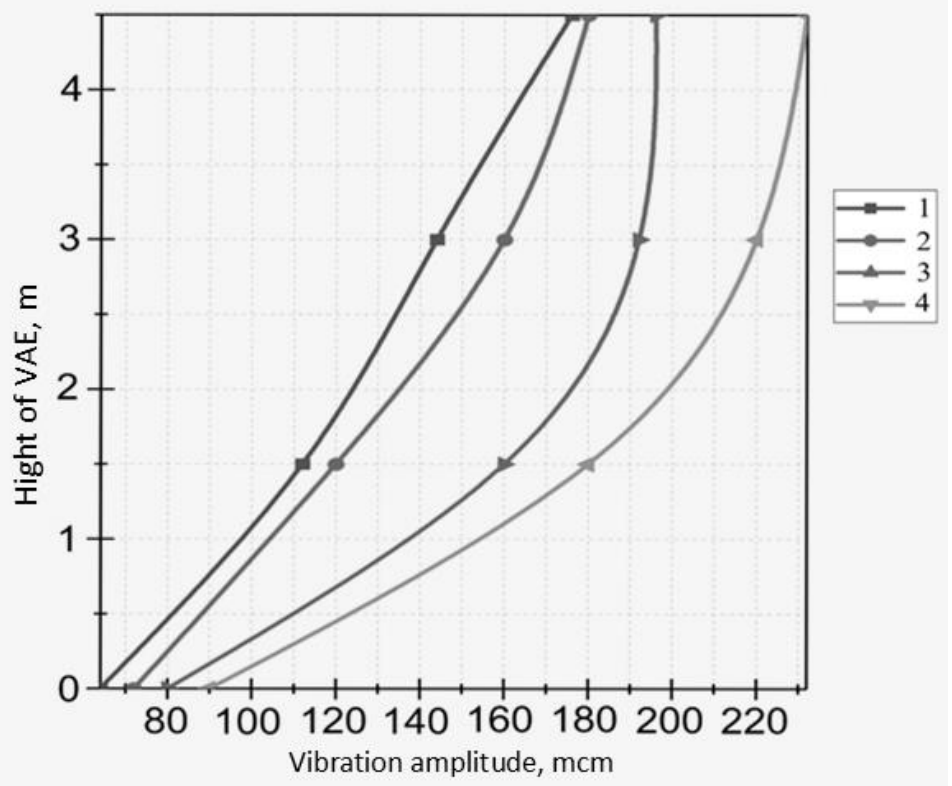

Fig. 4. Ground motion amplitudes by the periods: 1 - maximum frost penetration period (winter); 2 freezing period (autumn); 3 - maximum slump period settlements (summer); 4 - thawing out period (spring)

Figure 5 presents graphs for peak movements of VAEs №155 and №156 caused by the rolling stock moving along the tracks. Displacements of VAE are shown in relative values. Design proper position of the element is taken as reference mark and ground movement amplitudes are given in the graph as increment percentage against physical zero. The research 
shwed that VAE № 155 experiences maximum vibro-dynamic impact as compared with VAE № 156 with constructional protection measures applied.

VAE 156

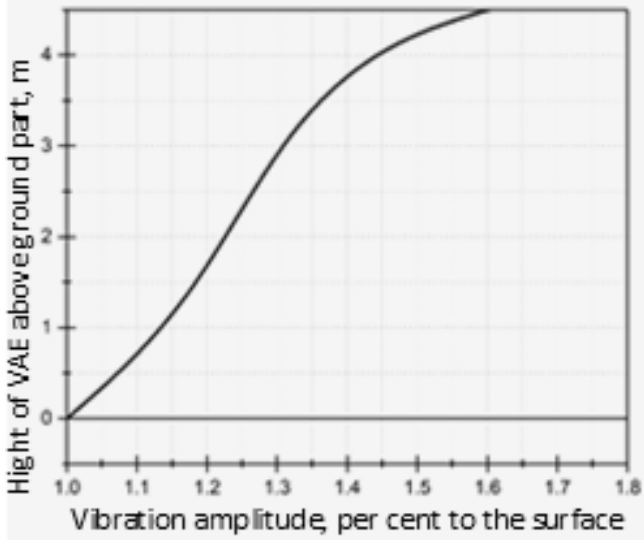

VAE 155

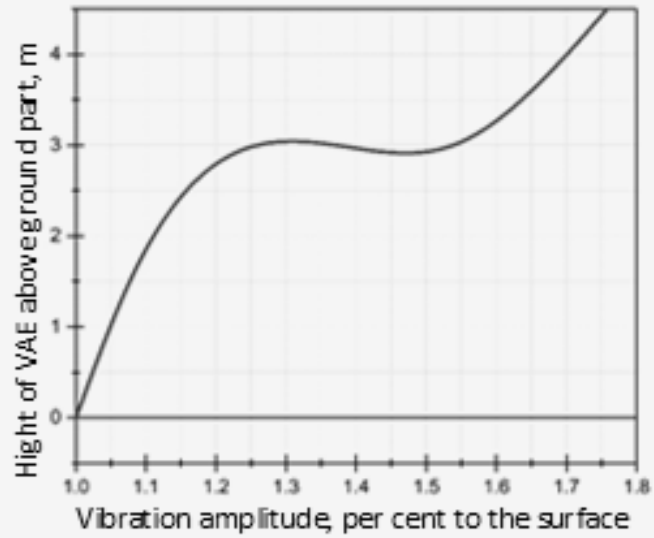

Fig. 5 Ground motion amplitudes: 1 - опора № 156; 2 - опора № 155

Ground movement process in the underground part of VAE №155 and №156 is presented in the terms of peak ground velocities $(\mathrm{m} / \mathrm{c})$. Figures 6 and 7 show peak ground velocities recorded by the null gage and the gage in the test pit at the target marking «-1.5 $\mathrm{m} »$.

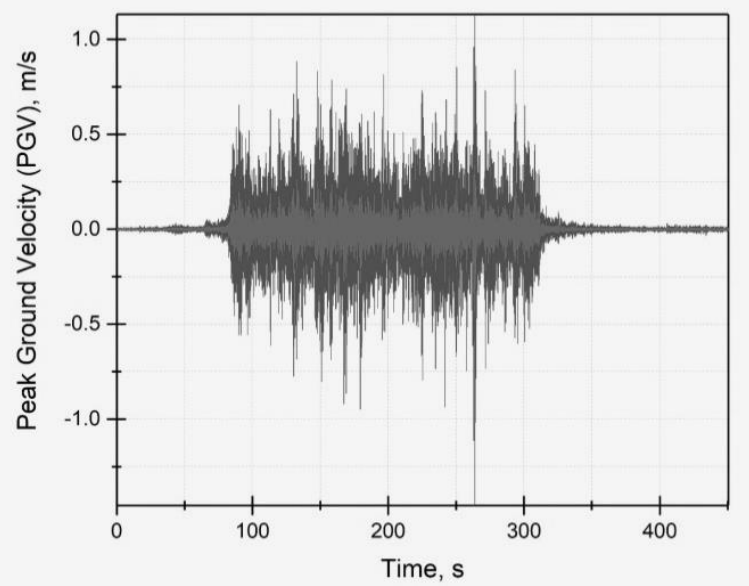

Fig. 6. Peak ground velocity at VAE №156 at the markings «0m» (black) and «-1,5 m» (red) correspondingly 


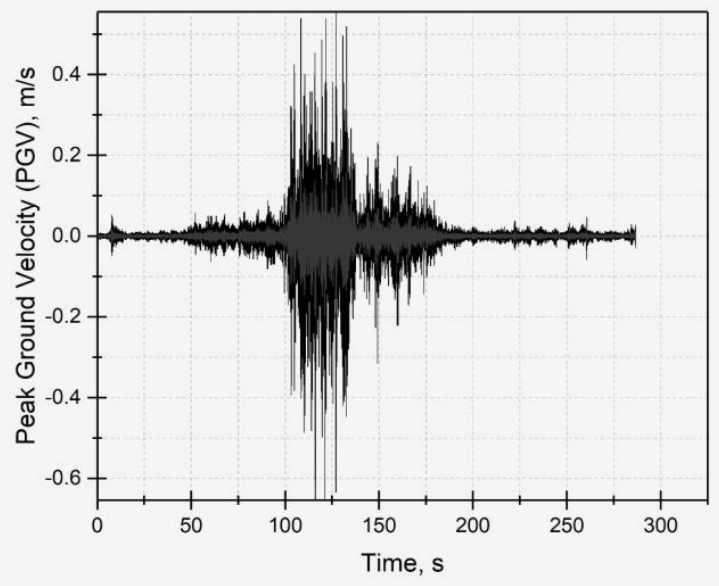

Fig. 7. Peak ground velocity of the foundation of VAE №155 at the targeting markings «0 m» $\mathrm{m}$ (black) and «-1.5 m» (red) correspondingly

Thus, increment in the ground velocity amplitudes display the changes in the wave properties that occur during the transition from the above ground part to the underground part of VAE and describe the physical-mechanical properties of the ground.

Analysis of the ground movement process of the submerged underground part of VAE showed that the peak ground velocities occur during the period of maximum thawing out of the ground. In winter period, the soil of the cut is frozen and the resilient ground reaction of such soil exceeds external impacts on VAE several times. Based on the research results obtained we make a conclusion about the zero level amplitudes of ground movements of the VAE underground part during the winter period.

As a result of the research conducted we also determined a seasonal reduction coeffcient of ground stregnth properties $\mathrm{D}$ due to the influence from the dynamic impact on the grounds around VAE

$$
\mathrm{Cu}=2,083 \mathrm{D} \text { e- } 0,137 \mathrm{w}
$$

$\mathrm{D}$ takes the following values: winter period $-\mathrm{D}=0.97$; autumn (pre winter) period $-\mathrm{D}=0.95$; summer period - $\mathrm{D}=0.90$; and spring period $-\mathrm{D}=0.85$

\section{Conclusions}

1. New opportunities for the development of the Russian economy are connected with the increase in the promptness of exploration of the northern and arctic regions of the Far Eastern Federal District. This requires well developed infrastructure : railways, motor ways, power lines and other structures built on seasonally frozen ground.

2. The laboratory experiments conducted on the triaxial compression test device in order to evaluate the impact of water content on the strength properties of the ground allowed us to determine the dependency of undrained shear strength on the water content in clay soils after thawing out.

3. Research into the dynamic impact on the ground of the foundations around vertical axial elements resulted in determination of the seasonal reduction coefficient of ground strength properties D; 
4. The dependencies obtained will allow a more precise modeling of the strain-deformation working condition of the grounds around VAE in seasonally frozen soils.

\section{References}

1. S.A. Kudryavtsev, U.B. Berestyanyy, T.U. Valtseva, et.al. International workshop on scrap tire derived geomaterials Opportunities and challenges Yokosuka, Japan. March 23-24, 171-178 (2007)

2. S.A. Kudryavtsev, U.B. Berestyanyy, T.U. Valtseva, et.al. 1st International conference on new developments in geoenvironmental and geotechnical engineering. November 9-11, University of Incheon. Korea. 423-427 (2006)

3. S.A. Kudryavtsev, T.U. Valtseva, et.al. 9th International Conference on Permafrost (NICOP) and the field trip followed at the University of Alaska Fairbanks in Fairbanks, Alaska. June 29-July 3, USA, 323-324 (2008)

4. S.A. Kudryavtsev, et.al. MATEC Web of Conferences, 106 (2016)

5. S.A. Kudryavtsev, Kazharsky A.V., et.al. Embankment on permafrost Eastern polygon of Baikal-Amur Mainline. International Scientific Conference on Transportation Geotechnics and Geoecology, Saint Petersburg, May 17-19, 2017. Russia. V.189, P. 774-782.

6. S.A. Kudryavtsev, A V Kazharsky et.al. Procedia Engineering, 165, 1080-1086 (2016)

7. S.A. Kudryavtsev, et.al. Procedia Engineering, 165, 1858-1865 (2016)

8. S.A. Kudryavtsev, et.al. MATEC Web of Conferences, 73, 05002 (2016)

9. S.A. Kudryavtsev, et.al. MATEC Web of Conferences 7305007 (2016)

10. S.A. Kudryavtsev, Soil Mechanics and Foundation Engineering, 45, 177-184 (2004)

11. I.A. Korotchenko, E.N. Ivanov, S.S. Manovitsky, V.A. Borisova, et.al. Magazine of Civil Engineering 69, 56-63 (2017), doi:10.18720/MCE.69.5

12. J. Kaikko, A. Mankonen, E. Vakkilainen, V. Sergeev, Energy Procedia 120, 572-579 (2017), doi:10.1016/j.egypro.2017.07.172

13. A. Fedyukhin, I. Sultanguzin, A. Gyul'Maliev, V. Sergeev, Eurasian ChemicoTechnological Journal 19, 245-253 (2017), doi:10.18321/ectj669 